\title{
Asthma diagnosis and treatment - 1008. Is small airways disease a widely prevalent yet underdiagnosed phenotype of asthma and COPD in India?
}

\author{
Sandeep Tandon ${ }^{1 *}$, Arvind Khutarkar ${ }^{1}$, Shabina Ansari ${ }^{2}$ \\ From 2nd WAO International Scientific Conference (WISC 2012) \\ Hyderabad, India. 6-9 December 2012
}

\section{Background}

Spirometry reports of many patients with clinical features of Obstructive Airways Disease (OAD) show predominant small airways(SAW) disease with reduced flow rates, but GOLD or GINA spirometric criteria not diagnostic of COPD or Asthma.

\section{Aims}

To compare small airways spirometric parameters with GOLD/GINA diagnostic parameters for COPD/Asthma in clinically and FlowVolume(FV) Loop-wise suspected OAD.

\section{Methods}

We retrospectively reviewed clinical data and spirometry reports of patients referred for preoperative respiratory fitness. We reviewed reports of patients whose histories, clinical findings and Flow-Volume Loop obstructive patterns were consistent with COPD/Asthma, but which were not diagnostic of COPD/Asthma based on the GOLD/GINA criteria. Data was analysed for 49 patients.

\section{Results}

Data comprised 14 males, 35 females, mean age $54 \mathrm{yrs}$ (31-72), $82 \%$ never-smokers. 44 had post bronchodilator studies. FEF75 or FEF25-75 $<65 \%$ were categorised as SAW disease. Pre bronchodilator (Pre-BD) Mean FEV1/ FVC was $78 \%$ (70-91\%), however Mean FEF75 and FEF25-75 (\% predicted) were $34.5 \%$ and $43.3 \%$ respectively. 6 patients had both, a reversibility in FEV1 $>12 \%$ and increase by $200 \mathrm{ml}$. Interestingly, of the remaining 38 patients who had no reversibility on a postbronchodilator study, 19 had $>30 \%$ reversibility in either FEF 25-75 or FEF75 (Mean reversibility of $53.5 \%$ ) with a mean post bronchodilator increase in flow rates of $506.3 \mathrm{~mL} / \mathrm{s}$. All patients improved symptomatically with inhaled bronchodilator \pm steroid therapy.

\section{Conclusions}

Small airways (SAW) disease is an important feature of both COPD and Asthma. Screening spirometry relying only on FEV1, FVC, FEV6 without small airways flow rates or visually documented obstructive pattern on FV Loops may miss SAW disease, thus underdiagnosing such phenotypes of COPD or Asthma which might be prevalent in Asian countries due to exposure to biomass fuel and air pollution.

\section{Author details}

'Pulmonary Medical Unit, Tata Memorial Hospital, Mumbai, India. ${ }^{2}$ Staff Clinic, Tata Memorial Hospital, Mumbai, India.

Published: 23 April 2013

doi:10.1186/1939-4551-6-S1-P8

Cite this article as: Tandon et al:: Asthma diagnosis and treatment 1008. Is small airways disease a widely prevalent yet underdiagnosed phenotype of asthma and COPD in India? World Allergy Organization Journal 2013 6(Suppl 1):P8.

'Pulmonary Medical Unit, Tata Memorial Hospital, Mumbai, India

Full list of author information is available at the end of the article

(c) 2013 Tandon et al; licensee BioMed Central Ltd. This is an Open Access article distributed under the terms of the Creative Commons 